\title{
Symptoms and signs
}

\author{
Shaun McCann ${ }^{1}$
}

Received: 10 December 2018 / Accepted: 10 December 2018 / Published online: 10 January 2019

(c) Springer Nature Limited 2019

\begin{abstract}
In Medical School it's quite possible to be taught that you can diagnose everybody and treat everything. But then you get out in the real world and find that for most patients walking through your door, you have no idea what's causing their symptoms.

Barry Marshall. Australian physician, Nobel Laureate and Professor of Clinical Microbiology. 1951-
\end{abstract}

I don't want to be pedantic but there are differences between symptoms and signs. Symptoms are what the patient complains of and signs are what the doctor sees or elicits. It is axiomatic that babies, animals, and plants cannot have symptoms, unless they can speak! Recently I had cause to phone the national radio station in Ireland when the newsreader said that sheep had symptoms of 'Foot-and-Mouth Disease'. I explained that sheep could not have symptoms unless, of course, they could speak. I have even heard veterinary surgeons speaking about dogs with symptoms. However some people including St Francis of Assisi and Dr Dolittle have been known to talk to animals. Of course languages evolve and words change meaning and pronunciation over time but symptoms and signs have very different meanings.

Do some wine writers fall into the same trap? Unfortunately the answer is yes. Wikipedia in its section on Botrytis cinerea mentions: 'Symptoms are visible...' and the website www.evineyardapp.com also writing about Botrytis cinerea contains a paragraph with the title 'Symptoms'. Perhaps these writers know something I don't and the infected grapes can talk! Infection of grapes, incidentally,

Shaun McCann

shaunrmccann@gmail.com

1 University of Dublin Trinity College, Haematology, Dublin, Ireland with Botrytis cinerea is prized in certain parts of the world as the infection is responsible for the famous sweet wines from Bordeaux and other places. (BMT https://doi.org/10. 1038/s41409-018-0237-y). Recently Andrew Jefford writing in the weekend FT (August 2018) attributes symptoms to vines/grapes of new deadly fungal diseases and the noted wine writer Jancis Robinson has been guilty of the same mistake.

Does it matter? Yes it does. As we educate medical students, the public and politicians it is essential that we are precise in our use of words. In medicine, and especially hematology, symptoms can be quite vague and signs may point you in the right direction about the diagnosis. Yet sometimes symptoms and signs may overlap. With enlarging lymph nodes for example a patient may complain of discomfort and examination rapidly confirms the sign of lymphadenopathy (Fig. 1). On the other hand some symptoms may be very vague and the signs may only be elicited by imaging or laboratory tests.

One of the complaints that patients make is that doctors do not make eye contact or touch their patients but turn to a computer and immediately order expensive laboratory of radiographic investigations. There is no doubt that there have been dramatic advances in laboratory (e.g., flow cytometry and molecular analyses) (Fig. 2) and radiographic investigations (CT and MRI) which allow us to pinpoint the extent of diseases and hopefully guide treatment but most patients like the doctor to hold their hand, put their arm around them and say: 'We'll do our best'. With the desire to find a cure, especially for hematological malignancies' we may forget that symptom relief is extremely important when treating incurable diseases. The quintessential disease, where a carefully taken history with microscopic examination of the urine followed by flow cytometry can make the diagnosis, is paroxysmal nocturnal hemoglobinuria. Unfortunately because a 'dip stick' cannot differentiate between hematuria and hemoglobinuria, these patients are often subjected to extensive and useless urological investigations. It is also important to remember that 


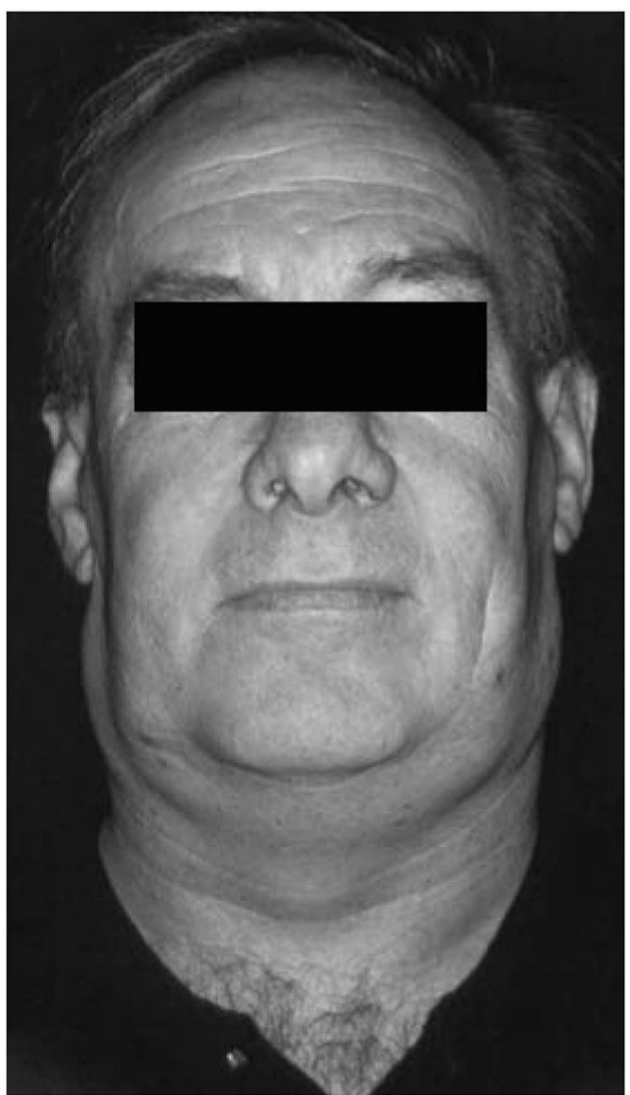

Fig. 1 Massive lymphadenopathy in a patient with CLL. Symptoms and signs overlap. With permission from Shaun R. McCann. From CCU hematology. Wiley/Blackwell UK. ISBN 978-1-4051-8322-2. 2009

Fig. 2 Flow cytometry analysis of RBCs from two patients with PNH. With permission from Shaun R. McCann and D O'Brien. From A History of Hematology: from Herodotus to HIV. Oxford University Press, UK. ISBN. 079-0-19$-871760-7.2016$ so-called grade 1 and 2 toxicities may be extremely important to patients and may be undervalued by doctors.

So as educators we should train our medical students to listen carefully to a patient's symptoms, examine carefully and with that combination, choose the appropriate investigations. Without being a pedant, please use terms that are precise and remember that 'aim' is a verb and 'target' and 'impact' are nouns. Unlike interacting with patients, one does not have to listen to wine to enjoy its putative benefits.

\section{Compliance with ethical standards}

Conflict of interest The authors declare that they have no conflict of interest.

Publisher's note: Springer Nature remains neutral with regard to jurisdictional claims in published maps and institutional affiliations. a

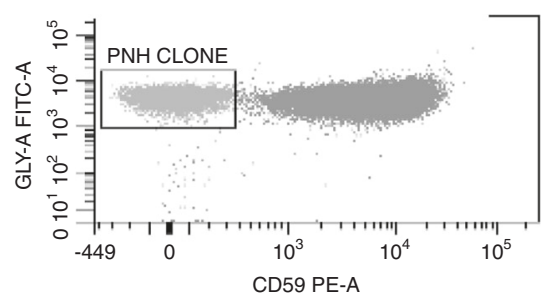

b

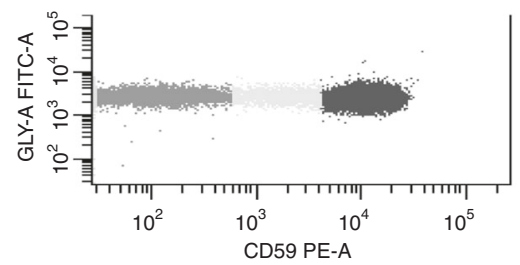

RBC Analysis
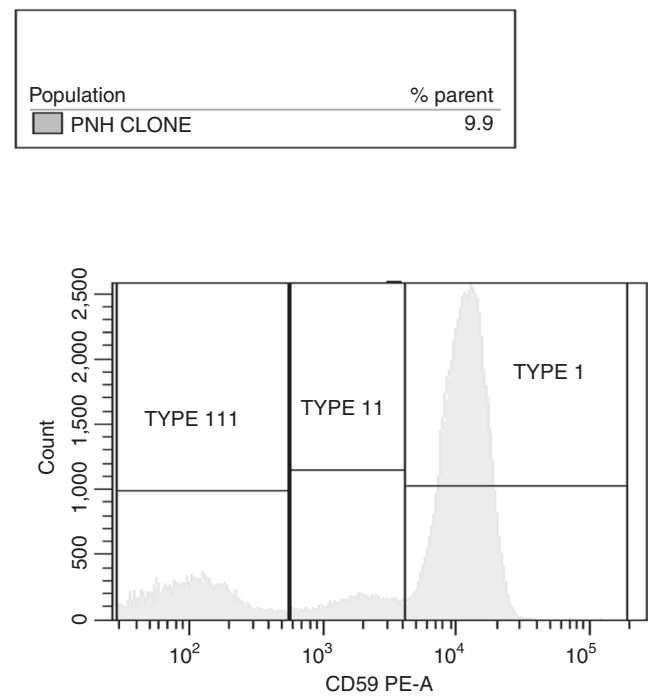